\title{
RESENHAS
}

REVIEWS

\section{DIREITO SANITÁRIO}

\begin{abstract}
Sueli Gandolfi Dallari e Vidal Serrano Nunes Jr. Editora Verbatim, São Paulo, 2010.
\end{abstract}

Jorge Luiz, Ussier ${ }^{(*)}$

Direito Sanitário, obra dos professores Sueli Gandolfi Dallari e Vidal Serrano Nunes Júnior, em recente edição da Editora Verbatim, em apenas cinco capítulos traça de forma clara e objetiva um completo estudo do direito à saúde.

No primeiro capítulo, os autores, revelam a saúde como um bem jurídico de três dimensões: individual, coletivo e de desenvolvimento, "assim pensado não só com base nas presentes, mas também nas futuras gerações".

Demonstrando com clareza que ninguém pode ser individualmente responsável por sua saúde, assim como é impossível a qualquer conceito de saúde ignorar a necessidade do equilíbrio interno do homem e desse com o ambiente, os autores descrevem um paralelo entre a evolução do direito e da saúde, concluindo que ambos requerem, no Estado Contemporâneo, a mais ampla compreensão do ambiente em que será realizado o direito à saúde, sugerindo que o direito à saúde exige tanto a participação do Parlamento como dos cidadãos na elaboração e implementação das normas e ações destinadas à promoção, proteção e recuperação da saúde.

(*) Procurador de Justiça, Coordenador Geral do Centro de Apoio Operacional das Promotorias de Justiça Cíveis e de Tutela Coletiva do Ministério Público de São Paulo. São Paulo/SP - Brasil. Recebido em 18.11.10. 
Ainda no capítulo inicial correlacionam o conceito contemporâneo do direito à saúde a aspectos ligados à organização internacional, e exemplificam os mecanismos internacionais criados para proteção da propriedade industrial em matéria de produtos de interesse para a saúde, como a Declaração de Doha que versa sobre a questão das patentes farmacêuticas e defende o acesso das pessoas aos medicamentos, dentre outras questões. Continuam exemplificando situações que comprovam a internacionalização dos direitos à saúde e, especificamente, o conceito de saúde nesse contexto internacional. O primeiro capítulo finaliza com a demonstração de que o direito sanitário é uma disciplina autônoma, mas que interage com outros ramos do direito, sendo, para os autores, mais significativa com o direito ambiental e o direito do consumidor.

O segundo capítulo circunscreve o direito à saúde, como direito fundamental, no contexto constitucional. Inicialmente os autores elencam e explicam as características dos direitos fundamentais: têm caráter histórico; são universais, irrenunciáveis e limitáveis. Ressalvam, ainda, que os direitos fundamentais podem concorrer entre si. Situam o surgimento dos direitos fundamentais e, em seguida, o distinguem na já conhecida divisão de direitos de primeira, segunda e terceira geração. Traçam um histórico do surgimento do direito social no mundo e, após, na ordem jurídica brasileira, enfocando-o na ordem constitucional. Em seguida, passam a discorrer sobre os princípios constitucionais do direito à saúde, tendo por norte sua fundamentalidade e a responsabilidade estatal, salientando que o direito à saúde é bem jurídico que deve ser tutelado pelo Estado não só como serviço prestado (direta ou indiretamente), mas, também, como atividade relevante.

Os autores discorrem sobre as implicações do acesso universal e igualitário do direito à saúde, apontando a diferença entre esses dois princípios e indicando sua correta interpretação. Explicam, ainda, a repercussão gerada quanto aos princípios da gratuidade e integralidade e passam a falar sobre o Sistema Único de Saúde: organização, atribuições e diretrizes, explicando o que se deve entender por sistema único, terminologia empregada pela Constituição Federal no art. 198, caput. Discorrem ainda sobre como a previsão do direito à saúde, como um sistema, repercute no modelo federativo. Com base no art. 5o da Constituição Federal, os autores apontam quais são os objetivos do SUS e extraem do art. 6음 da Lei Orgânica da Saúde as atribuições do sistema. Em seguida, enfocam a diretriz da descentralização com direção única em cada esfera de governo e explicam de que forma esse processo de descentralização ocorre em cada unidade da Federação: União, Estados e Municípios.

Para os autores, a diretriz de assistência integral tem por objetivo delimitar a extensão e o alcance do dever de atenção do SUS. Explicando de que forma essa diretriz deve ser interpretada, ao final, enfrentam a questão mais controversa com relação ao tema: expedientes administrativos podem delimitar a assistência integral? 
Os dois últimos tópicos do segundo capítulo enfocam a participação da comunidade - terceira diretriz do SUS - e a iniciativa privada e a assistência à saúde. Salientam os autores que a diretriz da participação da comunidade já se encontra regulamentada pela Lei n. 8.142/90, determinando que cada unidade federativa tenha duas instâncias colegiadas: a Conferência de Saúde e o Conselho de Saúde. Explicam, então, qual a função de cada uma dessas instâncias. No tocante à iniciativa privada e a assistência à saúde, Dallari e Serrano explicam de que forma a atuação da iniciativa privada pode ocorrer na saúde, seja ligada ao SUS, seja fora dele.

O terceiro capítulo do livro trata da repartição constitucional de competências e o Sistema Único de Saúde. Primeiramente, os autores discorrem acerca da competência de cada unidade da Federação com relação ao direito à saúde. Esclarecem, após analisar a competência da União, Estados, Distrito Federal e Municípios sob a ótica constitucional, que é evidente a responsabilidade conjunta de todos, o que implica que o cidadão pode demandar contra qualquer entidade federativa. Salientam, porém, que não obstante seja uma responsabilidade comum, cada um tem sua quota-parte, sendo que a Lei n. 8.080/90 repartiu a responsabilidade de cada ente, sendo que, segundo os autores, o Município é que detém a maior parcela de responsabilidade.

Fazendo nesse ponto uma breve digressão, alertam que o Ministério Público tem o dever de zelar para que os Poderes Públicos garantam o direito à saúde, e a Defensoria Pública tem o papel de orientar e defender os necessitados. A partir de então, tratam da Lei Orgânica da Saúde, enfocando, por exemplo, o que é vigilância sanitária, epidemiológica e saúde do trabaIhador, com base em dispositivos da Lei n. 8.080/90 e da Lei n. 8.142/90.

Aqui é importante frisar a explicação dada pelos autores sobre a origem dúplice da legislação de organização do sistema sanitário:

foi aprovado, em setembro de 1990, Projeto de Lei Orgânica da Saúde. Enviado para a sanção do Presidente da República, o projeto, com vários artigos vetados, transformou-se na Lei $n$. 8.080, de 19 de setembro de 1990. Os vetos apostos ao referido projeto de lei abrangiam os dispositivos que disciplinavam a participação da comunidade na gestão do sistema único de saúde e as transferências intergovernamentais de recursos financeiros na área da saúde. Em rara demonstração de efetiva participação do movimento popular em saúde, foi possível articularem-se pressões sobre o Poder Executivo e sobre o Congresso Nacional, que resultaram na promulgação, em 28 de dezembro de 1990, da Lei n. 8.142, que disciplinou a matéria que havia sido prejudicada pelos vetos apostos ao Projeto de Lei Orgânica da Saúde. Assim, no Brasil, tem-se uma situação esdrúxula no que respeita à legislação de organização do sistema sanitário, uma vez que a Lei Orgânica da Saúde, na realidade são duas: a lei n. 8.080 e a lei n. 8.142, ambas de 1990. 
Ainda nesse capítulo tratam das Comissões Intergestores e das normas operacionais básicas do sistema de saúde, instrumentos de gestão do sistema, responsáveis por reger a responsabilidade solidária entre os entes da Federação. Nesse contexto, os Autores detalham algumas normas operacionais básicas — desde algumas já revogadas e outras atuais - além de portarias, e falam sobre o Pacto pela Saúde, assim subdividido: o pacto pela vida, o pacto em defesa do SUS e o pacto de gestão. Finalizando o capítulo, os autores tratam da importância das políticas públicas de saúde, como ação governamental programada e planejada, através de planos municipais, estaduais e federais de saúde.

O quarto capítulo do livro aborda o sistema de vigilância sanitária, definindo o conceito, com base na Lei $n$. 8.080/90. Os autores salientam que o Poder Público regulou: as ações e os serviços públicos ou assemelhados destinados a promover, proteger ou recuperar a saúde (Leis n. 8.080/90 e 8142/90); os planos e seguros privados de assistência à saúde (Lei n. 9.656/98); e o sistema nacional de vigilância sanitária (Lei n. 9.782/99). Destacam que a edição desta última, definindo o Sistema Nacional de Vigilância Sanitária

dá, portanto, consequência lógica aos mandamentos constitucionais e legais que organizam o sistema de saúde no Brasil. É necessário observar que, enquanto organiza o Sistema Nacional de Vigilância Sanitária, essa lei tem característica de lei nacional. A lei reservou, assim, para a esfera federal, para a União, exclusivamente, a definição da política e do sistema nacional de vigilância sanitária, as atividades de normatização, controle e fiscalização de produtos, substâncias e serviços de interesse para a saúde e de vigilância sanitária de portos, aeroportos e fronteiras e todas as atividades executivas em situações especiais de risco à saúde. E atribuiu a todos os integrantes do conjunto federativo a manutenção do sistema de vigilância sanitária propriamente dito e de um sistema de informações em vigilância sanitária (lei federal n. 9.782/99, art. $2^{\circ}$ ). Essa mesma lei criou, para a execução das atividades de competência da esfera federal, a Agência Nacional de Vigilância Sanitária - ANVISA - admitindo a possibilidade de realização de convênios com as esferas estadual e municipal para a realização das atividades conjuntas, previstas no sistema.

Nesse contexto, os autores tratam do papel das agências reguladoras, especificamente da Agência Nacional de Vigilância Sanitária, concluindo que o Sistema Nacional de Vigilância Sanitária está apto para atender aos princípios constitucionais. Todavia, ressalvam que

para que se caminhe em busca da eficácia da norma regulamentadora em Vigilância Sanitária é necessário, contudo, perceber que o que se esconde efetivamente atrás do risco tecnológico é a enorme divisão do trabalho social, que corrompe a base da solidariedade orgânica que vinha sendo construída na modernidade. De fato, falar em prevenção 
de riscos nos domínios técnicos implica, além de testes severos de confiabilidade dos componentes, isolar as "causas" determinantes de possíveis acidentes "que podem ser controladas". Esconde-se, assim, que a fixação do limite de risco tolerável - que é necessariamente arbitrário - depende da valorização de aspectos econômicos, políticos e sociais, uma vez que o risco envolve atividades que se realizam no espaço social e que são resultado da colaboração social. Desse modo, quem decide que determinado evento natural (que possa ser quantificado) numa atividade social se transforme num risco, decide eticamente, ponderando valores. Ou seja, tanto o evento que origina o risco é social quanto a sua percepção é pública.

Enfrentam a questão da Vigilância Sanitária e repartição de competências, destacando que: a) à União se outorgam atividades de aspectos normativos e regulatórios; b) aos Municípios, funções executivas de implementação concreta das leis e normas administrativas em vigor; c) aos Estados a coordenação do sistema, a assistência técnica e financeira aos Município e, eventualmente, a suplementação das atividades desenvolvidas por estes.

Especialmente sobre a ANVISA, esclarecem, com base na Lei n. 9.782/99, quais as suas competências e os produtos submetidos ao controle e fiscalização sanitária da agência. Tratam ainda do Poder de Polícia em matéria sanitária e do processo administrativo, explicando seus princípios (legalidade objetiva, oficialidade, publicidade, formalismo moderado, verdade material, atipicidade, contraditório e ampla defesa) e suas fases (instauração, instrução, defesa, relatório e julgamento).

Coroando a obra, o último capítulo aborda o tema da propriedade intelectual, suas interfaces com o direito e, em especial, com o direito à saúde. Inicialmente, os autores traçam um panorama geral acerca da propriedade intelectual, salientando que o interesse do tema

para o Direito Sanitário é muito claro, pois a atenção à saúde implica a utilização constante de equipamentos, insumos, medicamentos etc., os quais se encontram em constante evolução, e, portanto, patenteamentos desses bens de interesse para a saúde são frequentes, $o$ que, de um lado, assegura uma evolução tecnológica constante para aperfeiçoar o sistema, mas, de outro, traz riscos para a saúde (por exemplo, efeitos colaterais não conhecidos de um medicamento) e impacto econômico tanto na esfera pública como na privada de atenção à saúde. Por isso, a dicção do art. 200, I, da Constituição Federal preconizando competir ao sistema único de saúde "controlar e fiscalizar procedimentos, produtos e substâncias de interesse para a saúde e participar da produção de medicamentos, equipamentos, imunobiológicos, hemoderivados e outros insumos. 
Discorrem acerca da Política Nacional de Medicamentos, parte da Política Nacional da Saúde, a qual, segundo os autores, foi desenvolvida em conformidade com as orientações da Organização Mundial da Saúde (OMS) em três eixos: Regulação Sanitária, Regulação Econômica e Assistência Farmacêutica, sendo que a ANVISA é a responsável em garantir que os medicamentos consumidos pela população brasileira não causem danos à saúde, além de monitorar sua produção e comercialização. Nesse contexto, abordam o papel da ANVISA e do registro de patentes, esmiuçando o processo de registro de patentes.

Retornando à definição do conceito de saúde, discorrem acerca da reivindicação do "direito à saúde" e da sua relação com os "direitos humanos", apontando semelhanças entre ambos. Tratam do processo de urbanização - consequência imediata da industrialização - e sobre como este processo contribuiu para a conscientização de que "o Estado deve responsabilizar-se pela saúde do povo". Os autores trazem a questão para os dias atuais, sob a ótica do Estado e da saúde pública, salientando que no mundo contemporâneo "o nível de saúde de um povo é dependente do seu nível de desenvolvimento sócio-econômico e cultural".

Em seguida, relacionam os elementos históricos e sociais para fazer o leitor compreender "o alcance das normas de direito sanitário do século vinte e um". Partem da época do Renascimento e da experiência da Alemanha com as epidemias, desencadeando a ideia de polícia médica. Passam pelo lluminismo de fundamental importância por "não admitir as explicações sobrenaturais para os fenômenos naturais" e pelo período da Restauração (1814 - 1a queda de Napoleão - 1830 - revolução de julho, queda de Charles X), ocasião que surgiram as "primeiras leis que tratavam organicamente da higiene urbana, da noção de estabelecimento insalubre e do controle sanitário de fronteiras".

De acordo com os autores, apenas na segunda metade do século XIX "a higiene passa a ser reconhecida como um saber social, que envolve toda a sociedade e faz da saúde pública uma prioridade política". Com relação ao início do século XX, explicam que foi nesse período em que se consolidou a "proteção sanitária como política do Estado", sendo hierarquizadas as três formas de prevenção: primária, secundária e terciária, sendo que: 0 Estado do Bem-estar social da segunda metade do século XX reforça a lógica econômica, especialmente em decorrência da evidente interdependência entre as condições de saúde e de trabalho, responsabilizando-se pela implementação da prevenção sanitária.

Nesse contexto, surgem os institutos de previdência social, que englobam "os sub-sistemas de assistência, previdência e saúde públicas". Salientam que nos últimos anos do século XX surgiu uma nova concepção de saúde pública, decorrente do "relativo fracasso das políticas estatais de 
prevenção", e "da importância decisiva de comportamentos individuais no estado de saúde", sendo que a prevenção sanitária passou a ser vista sob a ótica do custo-benefício.

Os autores ressaltam que a "saúde pública representa, sem qualquer dúvida, uma evidência na mudança de paradigma no campo da saúde" e chegam no ordenamento jurídico brasileiro e no papel do Estado sob a ótica da Constituição de 1988.

Ao final, tratam do tema política de medicamentos, enfrentando diversas questões, dentre elas, o conflito de dois direitos: o direito à saúde e o direito à propriedade industrial. Os autores elencam práticas que implicam em licença compulsória da patente, de acordo com a disciplina do abuso de direitos.

Direito Sanitário, obra de Sueli Gandolfi Dallari e Vidal Serrano Nunes Júnior, percorre todo o caminho do direito à saúde até o momento atual, e ajuda a abrir caminhos para o seu desenvolvimento neste século XXI. 